\title{
The Berlin 2014 Water Management Workshop
}

\author{
Jonas Berking ${ }^{1}$
}

Published online: 1 March 2016

(C) Springer Science+Business Media Dordrecht 2016

In February 2014, the Cluster of Excellence Topoi organized a workshop on ancient water management at their home institution the Freie Universität Berlin, Germany. Already months before the workshop, it was a pleasure to learn, that Springer's Water History would be ready to publish any good outcomes in a special issue and moreover that Maurits Ertsen would show up to give the initial talk.

The topics of the workshop were-historically and geographically-wide spread, ranging from the earliest riverine states to medieval societies and from Latin America to Central-East Asia. Nevertheless, a clear focus on Mediterranean landscapes and the classic antique societies prevailed. This focus is explained by the attending scientific community and range of disciplines that framed this workshop. This community was composed of disciplines as different as Engineering, Legal Studies, History, Ethnology, Geology, Geography and Archaeology. The workshop benefitted from a well-selected, compact small participating group, with a series of shorter talks and, plenary talks allowing more time for discussions between all.

A bit contrary to the good presentations and positive feedbacks during and after the workshop are the accepted papers that have made it into this volume of Water History, which only total two. The first paper by Delphine Driaux discusses water supply of ancient Egyptian settlements, with particular attention of the role of the state. Through her overview of a one specific scheme in the Old to New Kingdom (ca. 2543-1077 BC), Driaux proves to be a good example of an Egyptologist, who really shows that with a different perspective on ancient Egyptian societies, new and interesting research results can be achieved. In the second paper presenting a history of water and society in the region of Vélez Blanco, East Andalusia, a group of authors consisting of Dietmar Roth, Brian Beckers, Jonas Berking, Sarah Isselhorst and Brigitta Schütt present the long time depth of

Jonas Berking

jonas.berking@fu-berlin.de

1 Fachbereich Geowissenschaften, Institut für Geographische Wissenschaften, Fachrichtung Physische Geographie, Freie Universität Berlin, Malteserstraße 74-100, 12249 Berlin, Germany 
a Spanish irrigation community and its intriguing legal history. With these papers, two well written and original studies reflect the wide range of time and topics discussed during the workshop.

Please see for the general organization of the Topoi initiative http://www.topoi.org/.

Please find more detail about the Topoi water management group at http://www.topoi. org/group/water-management/.

Details of the 2014 workshop can be found at http://www.topoi.org/event/21284/. 